\title{
os herdeiros de Leverger
}

Valmir Batista Corrêa ${ }^{* *}$

Este estudo trata da historiografia mato-grossense e diz respeito à influência exercida por Augusto Leverger nos estudos históricos e geográficos sobre Mato Grosso, a partir da segunda metade do século XIX. Da geração de historiadores que fundaram o Instituto Histórico e Geográfico de Mato Grosso em 1919, influenciados diretamente pelo trabalho de Leverger, destacaram-se Virgílio Corrêa Filho, Antonio Fernandes de Souza e Estevão de Mendonça.

Palavras-chave: Historiografia; História regional, Mato Grosso.

This is a mato-grossense historiography study focusing on the influence of Augusto Leveger at the Mato Grosso historical and geographic studies from the Late XIX century. From the historitian genration that founded the Instituto Histórico e Geográfico de Mato Grosso at 1919, Virgílio Corrêa Filho, Antonio Fernandes de Souza, and Estevão de Mendonça were directly influenced by Levenger's work.

Key words: Historiography; Local history, Mato Grosso.
A geração de historiadores nascida nas últimas décadas do século XIX, marcadamente em Cuiabá, e que participou ativamente da fundação do Instituto Histórico de Mato Grosso em 1919, não pode ser compreendida e estudada desvinculada da presença e da atuação intelectual de Augusto Leverger. Dentre os historiadores que buscaram valorizar e resgatar documentalmente a história de Mato Grosso, sem dúvida, os que mais receberam influências das pesquisas históricas e geográficas de Leverger (por isso mesmo, seus biógrafos) foram Estevão de Mendonça, seu maior discípulo, Virgilio Corrêa Filho e Antonio Fernandes de Souza.

\footnotetext{
*Versão revisada e ampliada do artigo publicado na Revista do Instituto Histórico e Geográfico de Mato Grosso. Edição comemorativa aos 75 anos de fundação do IHGMT, 1919 - 1994. Ano LXVI, tomos CXLI - CXLII. Cuiabá: IHGMT, 1994, pp. 271-287.

*** Professor doutor em História, titular aposentado da UFMS.valmir.correa@uol.com.br
} 
Marinheiro francês, engajado na Armada Imperial Brasileira em 1824 com 22 anos, Augusto Leverger, o "bretão cuiabanizado" no dizer de Virgilio Corrêa Filho ${ }^{1}$, chegou pela primeira vez em Cuiabá em 1830, como comandante das canhoneiras empregadas no rio Paraguai, retirando-se em março de 1834 em plena efervescência das manifestações nativistas que ocorriam em várias partes da província. Retornando a Cuiabá em 1837, Leverger exerceu atividades militares e diplomáticas, realizando inclusive o primeiro reconhecimento geográfico do rio Paraguai. Iniciava-se assim a produção de inúmeros trabalhos de levantamentos, "diários", "roteiros de navegação" e descrição de "vias de navegação". Delineava-se ao mesmo tempo um traço marcante de sua personalidade de raramente escrever de forma espontânea, mas sempre "instigado por algum motivo especial"" ou por determinação de autoridades provinciais. Sua humildade intelectual foi atestada por Virgilio Corrêa Filho referindo-se aos seus trabalhos, afirmando que Leverger "não cogitava em vê-los impressos, embora estivesse atento sempre a

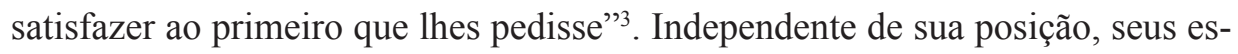
tudos começaram a ser divulgados além da Província de Mato Grosso através da revista do Instituto Histórico e Geográfico Brasileiro, do qual se tornou membro em 1848. Foram publicados os escritos "Carta e Roteiro da navegação do rio Cuiabá desde o Salto até o Rio São Lourenço e deste último até sua confluência com o Paraguai", "Diario do Reconhecimento do Rio Paraguai desde Assunção até o Rio Paraná", "Observações sobre a Carta Geografica da Provincia de Mato Grosso", "Roteiro da Navegação do rio Paraguai, desde a foz do Sepotuba até o rio São Lourenço" e "Roteiro da Navegação do Rio Paraguai desde a foz do São Lourenço até o Paraná" (v. 25, 1862), "Breve Memória à Chorographia da Provincia de Mato-Grosso" (v. 28, 1865) e "Apontamentos para o Diccionario Chorographico da Provincia de Mato-grosso" (t. 47, 1883).

Naturalizado brasileiro e na patente de Capitão de Mar e Guerra, em outubro de 1850 Leverger acabou nomeado presidente da província, exercendo por 4 vezes este cargo em um período de mais de 7 anos. Esta presença constante

${ }^{1}$ CORRÊA F, Virgilio. A. Leverger (o bretão cuiabanizado). Terceiro Congresso de História Nacional, 2. Anais... Instituto Histórico e Geográfico Brasileiro. Rio de Janeiro: Imp. Nacional, 1941. p. 389-493.

${ }^{2}$ Idem, ibidem, p. 476.

${ }^{3}$ Idem, ibidem, p. 476. 
de Leverger na administração de Mato Grosso demonstrou também a consolidação de seu prestígio local, angariado através de suas atividades administrativas e dos trabalhos escritos sobre a história e à geografia da região. Foi filiado ao Partido Conservador, mas segundo Estevão de Mendonça, "filiado em termos, porque não cessava de explicar: ou a política não me serve, ou não sirvo eu para a política"4. Na verdade, gostava de afirmar que não participava de política por ser militar e estrangeiro.

Desse modo, tornou-se comum encontrar nos trabalhos que se referem a Leverger o realce do seu espírito tolerante e avesso à política. Virgilio Corrêa Filho, por exemplo, ressaltou que "abstraindo-se da política partidária, para melhor administrar, Leverger diligenciou suprir pelo trabalho e dedicação a escassez de meios que lhe amortecia as iniciativas"5. Mesmo assim conseguiu Leverger estabelecer normas pedagógicas para a instrução pública na província e voltou a sua atenção para as vias de comunicação. Ressalta ainda Virgilio Corrêa Filho que Leverger "trouxe a paz aos espíritos", sendo inclusive "por todos aplaudido e festejado como hábil administrador"7.

Foi, no entanto, com a invasão paraguaia no sul da província e a possível penetração dos invasores em Cuiabá através do rio Paraguai, que a participação de Leverger selou de forma definitiva a sua identificação com Mato Grosso. Seu prestígio e carisma conseguiram conter o pânico que se estabeleceu na capital, não somente entre a população civil como também junto aos militares ali estabelecidos. Sua atuação decisiva levou o Visconde de Taunay a defini-lo como o "antemural do Brasil em Matto Grosso". Em discurso na câmara dos deputados, em 16 de abril de 1877, assim se expressava Taunay:

A população tomada de pavor, sem chefe, allucinada, tratava de abandonar em massa os seus lares, deixando ao azar da sorte suas casas, commodos, e haveres, quando a 20 de janeiro de 1865 , o Sr. Leverger, ainda que alquebrado pelos annos e molestias, se apresentou resoluto e unico para iniciar e dirigir a resistencia. Deu-se então repentina e completa inversão no espirito publico; todos cobraram coragem, se reanimaram, correram ás armas, e o velho guerreiro, no

\footnotetext{
${ }^{4}$ MENDONÇA, Estevão. E foi naquela noite de Natal. Cuiabá, 1970. p.72.

${ }^{5}$ CORRÊA F, Virgilio. Op. cit., p. 429.

${ }^{6}$ Idem, ibidem, p. 431.

${ }^{7}$ Idem, ibidem, p. 431.
} 
meio de patrioticas ovações e de immenso enthusiasmo partiu, sem se despedir da sua familia, a occupar o ponto do Melgaço e fazer frente ao invasor ${ }^{8}$.

Por tal gesto, Leverger recebeu em novembro deste mesmo ano o título de Barão de Melgaço. No calor da hora, Leverger registrou os eventos iniciais da guerra em Mato Grosso numa "Synopsis da Historia da Invasão Paraguaya na mesma Província"9

No final de sua vida e longe das atividades públicas, Leverger dedicou-se integralmente aos seus escritos e estudos. Segundo Pimenta Bueno,

o venerando sr. Barão de Melgaço possuia um precioso arquivo de cópias interessantes, de documentos gráficos, com os quais organizou a carta de provincia, em 1868: entre esses documentos tinha muitos seus, relativos à história e geografia da provincia e do reconhecimento dos rios Cuiabá, Paraguai, do distrito de Miranda e outras localidades ${ }^{10}$.

Em 14 de janeiro de 1880, em Cuiabá, faleceu Augusto Leverger, deixando uma marca profunda na história de Mato Grosso e nos jovens intelectuais mato-grossenses. Ainda sobre Augusto Leverger afirmou o Visconde de Taunay de maneira emocionada e ufanista que

ao inclyto Augusto Leverger, barão de Melgaço, cabe perfeitamente o alentado appelido de Ricardo Franco do Brasil-Imperio, do mesmo modo que áquelle eminente militar é applicavel o de Augusto Leverger dos tempos Coloniaes. Ambos se valem pelo conjunto de qualidades scientificas, civicas e guerreiras, honestidade, habitos de trabalho, superioridade de vistas, desinteresse, modestia, pundonor e profundeza de conhecimentos technicos ${ }^{11}$.

\footnotetext{
${ }^{8}$ TAUNAY, Visconde. Augusto Leverger. Almirante Barão de Melgaço. Antemural do Brasil em Matto Grosso. Com um complemento da lavra de Virgilio Corrêa Filho. São Paulo: Melhoramentos, s/d. p. 13.

${ }^{9}$ Relatorio apresentado ao Illm. e Exm. Chefe de Esquadra Augusto Leverger Vice-Presidente da Provincia de Matto Grosso pelo Brigadeiro Alexandre Manoel Albino de Carvalho ao entregar a administração da mesma Provincia em agosto de 1865. Contendo a Synopsis da Historia da Invasão Paraguaya na mesma Provinica. Rio de Janeiro: Typ. do Commercio, 1866.

${ }^{10}$ Citado in: CORRÊA F, Virgilio. Op. cit., p.478.

${ }^{11}$ TAUNAY, Visconde. Augusto Leverger. Almirante Barão de Melgaço (1802-1880). In: Estrangeiros illustres e prestimosos no Brasil (1800 - 1892) e outros escriptos. São Paulo: Melhoramentos, s/d. p. 68. O seu arquivo particular, de acordo com o testamenteiro Cesario Corrêa da Costa, teve o seguinte destino: "Os livros aproveitaveis foram doados à Biblioteca da Instrução Pública de Mato Grosso (...). Os "apontamentos para o dicionário corográfico da Provincia de Mato Grosso", e "cronológicos", endereçados a Beaurepaire Rohan, chegaram, a 7 de Dezembro de
} 
Além dos trabalhos de Leverger, inúmeros estudos e relatos sobre Mato Grosso foram divulgados até o final do século XIX. A Revista do Instituto Histórico e Geográfico Brasileiro, por exemplo, em vários momentos abrigou em suas páginas trabalhos referentes à região, como de Ricardo Franco de Almeida Serra, Luis d'Alincourt, João Antonio Cabral Camello, Marcelino Rodrigues Camponês, Joaquim da Costa Siqueira. Outras revistas também chegaram a publicar trabalhos sobre a região, como a Revista do Instituto Histórico e Geográfico de São Paulo, a Revista da Sociedade de Geografia do Rio de Janeiro e os Anais da Biblioteca Nacional ${ }^{12}$. Havia, portanto, um crescente interesse em conhecer e divulgar Mato Grosso acentuado pelo trauma provocado com a guerra da Tríplice Aliança.

Com a proclamação da República, acabando com a costumeira gangorra da política imperial caracterizada pela alternância no poder dos partidos Liberal e Conservador, logo de início provocou em Mato Grosso uma acirrada disputa pelo controle da máquina administrativa estadual. A polarização da política mato-grossense deu-se então em torno de agremiações partidárias lideradas por coronéis oligarcas, trazendo ao seio da sociedade local o germe do divisionismo muitas vezes estigmatizado em pólos irreconciliáveis. Iniciou-se com a república um período conturbado da política mato-grossense com manifestações revolucionárias em várias partes do estado. Muitas dessas lutas coronelistas, pelas dimensões alcançadas, conseguiram convulsionar praticamente todo o Mato Grosso, provocando derrubadas (substituições) de governos estabelecidos. Assim ao entrar no século XX, a radicalização política em Cuiabá com reflexos em todos os municípios mato-grossenses marcou não somente as atividades político-partidárias como também as manifestações sócio-culturais regionais.

De fato, a forte presença do estado oligárquico numa sociedade onde a base do poder residia na posse da terra, como era o caso de Mato Grosso, provocava uma inter-relação de dependência entre diversos setores da sociedade. Nessas re-

1882, ao Instituto Histórico Brasileiro, em cuja revista só os primeiros vieram a lume, bem como os roteiros e diários de navegação. As notas avulsas foram ter às mãos de Estevão de Mendonça, que, dedicado ao culto levergeriano, em parte as fez publicar no Arquivo de Cuiabá e Revista de Mato Grosso. In: CORRÊA F, Virgilio. Op. cit. Nota 13, p. 479.

${ }^{12}$ Paralelamente às publicações em revistas oficiais, inúmeras publicações avulsas também foram editadas sobre Mato Grosso nesse período. Ver: SILVA, Paulo Pitaluga Costa e. Estudo Bibliográfico da História, Geografia e Etnologia de Mato Grosso. Cuiabá: CCS, 1992. 
lações de dependência, as atividades intelectuais e literárias não poderiam escapar dos tentáculos do controle estatal. Em primeiro lugar, era comum encontrar entre os intelectuais cuiabanos, por exemplo, funcionários públicos e professores exercendo cargos de confiança junto ao governo estadual. Eram atividades que garantiam a disposição de tempo para a realização de pesquisas e elaboração de trabalhos históricos e literários. Essa situação era, em contrapartida, eventualmente afetada por qualquer instabilidade política. Em segundo lugar, as relações de dependência com o poder estadual apareciam com clareza por ocasião da publicação e divulgação de suas obras literárias ou históricas. Enfim, todas as publicações mato-grossenses dependiam de financiamento público. Assim, a chamada publicação oficial contava, em última instância, com a boa vontade dos governantes. Os intelectuais cuiabanos ficavam dessa forma à mercê das crises políticas, podendo cair ou não em desgraça perante os novos governantes. Com justa razão, a impressão de um livro em Cuiabá, para José de Mesquita, era "uma das formas modernas de heroismo"13.

A descrição que Estevão de Mendonça traça sobre a passagem do século em Cuiabá, sob a influência levergeriana de equidistância política, mostrou de maneira clara e singela que mesmo em festas populares a cizânia política entre situação e oposição persistia na sociedade cuiabana.

O então presidente do Estado, coronel Antonio Pedro Alves de Barros, após sumptuoso baile, dado em sua residencia particular, ao signal das 12 horas, fez interromper da dança, que ia animada, e tomando de uma taça de champagne saudou os seus amigos ali reunidos, pela entrada do seculo XX. Uma banda militar executou o himno nacional, sendo queimada uma girandola de foguetes. Conduzidos pela esposa do presidente, diversas senhoras e cavalheiros dirigiram-se para o interior da residencia, sendo-lhes ali servido opiparo banquete. Além das autoridades locaes, outras pessôas de destaque encontravam-se presentes e entre estas os generaes Arthur Oscar e Alfredo Piragibe, coronel Antonio Paes de Barros, commandante Francisco M. Wanderley e dr. João de Moraes e outros. Ao mesmo tempo que assim se commemorava o findar do século XIX, tambem na residência do coronel Generoso Ponce, chefe politico da opposição, organizavam-se jogos de prendas, concerto, danças e jantares. A sociedade alí reunida não era menos selecta. Á meia noite diversas senhoritas, acompanhadas por uma orchestra dirigida pelo capitão Abilio Noronha, can-

${ }^{13}$ MENDONÇA, Rubens de. História da Literatura Mato-Grossense. Cuiabá: Ed. do Autor, 1970. p. 37. 
taram um mavioso himno, ao qual seguiram-se variadas contradanças. Pelas ruas da cidade turmas de rapazes recitavam cançonetas, e o mimoso jardim Alencastro regorgitava de passeiantes ${ }^{14}$.

Era a aparente calmaria antecedendo a violência política que iria ensanguentar a história mato-grossense nas primeiras duas décadas do século XX.

No entanto, dois momentos nessa época foram altamente favoráveis aos intelectuais cuiabanos pelo apoio ostensivo que receberam do estado na divulgação e na publicação de seus escritos. O primeiro momento ocorreu no governo do coronel Antonio Paes de Barros - Totó Paes (1903-1906), encerrado por crise política e revolucionária, e no segundo, como resultado de outra crise no governo de D. Francisco de Aquino Corrêa (1918-1922). Fora desses dois períodos de grande gravidade política, foram raros os momentos em que trabalhos historiográficos obtiveram divulgação e publicação com o aval do governo estadual. Nesses momentos, eram nos jornais cuiabanos que os escritores procuravam refúgio no campo da literatura e da história.

Contrapondo com o rastro de violência em que foi envolvido de forma direta ou indireta, o coronel Totó Paes tomando posse do governo mato-grossense procurou cercar-se de intelectuais e literatos para administrar o estado. Segundo Antonio Fernandes de Souza, seu chefe de gabinete, "todos esses homens de reconhecido valor intelectual e impoluta reputação moral e civica, prestaram valiosa colaboração à política, à administração e à cultura do Estado"15. No entanto, os fatos demonstraram que tal participação não impediu a radicalização política e a explosão de violência que envolveu Mato Grosso.

${ }^{14}$ MENDONÇA, Estevão de. Datas Mato-Grossenses. Nictheroy: Esc. Typ. Salesiana, 1919. 2 V., p. 376.

${ }^{15}$ SOUZA, Antonio Fernandes de. Antonio Paes de Barros (T'ótó Paes) e a Politica de Mato-Grosso. Cuiabá: Ed. do Autor, 1958. p. 55. Entre os membros do governo, Souza cita João Francisco de Novais Paes Barreto, "de reconhecida ilustração"; Antonio Vieira de Almeida, "jornalista, contista e emérito orador"; José de Freitas Cabral, "jornalista”; Januário da Silva Rondon, "consagrado latinista"; Pedro Trouy, "jornalista e poeta"; Carlos Leopoldo Jorge Salaberry, "advogado e jornalista"; Francisco Mariani Wanderley, "apreciado escritor"; Vital Batista de Araujo, "primeiro diretor do órgão oficial do estado, intitulado A Gazeta"; Francisco Agostinho Ribeiro, "jornalista e advogado"; e Estevão de Mendonça, “escritor e notável historiador”. p. 54. Generoso Ponce F por sua fez, e obviamente, colocou uma visão radicalmente oposta à posição de Antonio Fernandes de Souza com relação ao presidente Totó Paes e seu governo. In: PONCE F, Generoso. Generoso Ponce, um chefe. Rio de Janeiro: Pongetti, 1952. p. 381. 
Em janeiro de 1904, iniciou-se em Cuiabá a edição da "Revista Matto-Grosso", uma "Publicação Mensal de Sciencias, Lettras, Artes e Variedades", por iniciativa de padres salesianos. Além da divulgação da doutrina religiosa, a revista contava com colaboradores como Antonio Fernandes de Souza, Firmo Rodrigues e Estevão de Mendonça que deu início a publicação de suas "datas mato-grossenses". Também foram transcritos nesta revista textos de Jose Augusto Caldas, de Augusto Leverger com uma sequência de seus "Apontamentos Chronologicos da Provincia de Matto-Grosso" e de Ricardo Franco de Almeida Serra. Nos textos de Leverger e de Serra apareceram sempre a observação "Publicação feita sob a direcção de Estevão de Mendonça".

Curiosamente, na edição de agosto de 1907, provavelmente como reflexo dos fatos políticos e fugindo de suas características, a "Revista Matto-Grosso" estampou a foto do presidente empossado, coronel Generoso Paes Leme de Souza Ponce ressalvando, entretanto, em seu editorial que "esta publicação mensal não tem absolutamente feição politica, como bem se póde deprehender do seu programma e dos fins que determinaram a sua fundação; pelo que este seu procedimento para com o proeminente vulto politico, que se destaca não só neste Estado como em todo o Brasil, nada mais significa do que uma respeitosa homenagem prestada á primeira auctoridade constituida do Estado, da qual é depositario um matto-grossense veneravel, illustre por todos os titulos e credor da benemerencia publica pela correcção dos seus actos sempre vasados nos moldes da mais sã justiça, do mais ponderado criterio e do mais acrysolado patriotismo"16. A publicação da "Revista Matto-Grosso" durou até por volta de 1914.

No mesmo ano de 1904, teve início a publicação de "O Archivo" (19041906), afirmando ser uma "revista destinada á vulgarisação de documentos geographicos e históricos do Estado de Matto-Grosso" e realçando que era uma "publicação feita sob os auspicios do Exmo. Senr. Coronel Antonio Paes de Barros". Sob a direção de Estevão de Mendonça e de Antonio Fernandes de Souza, seus idealizadores, a revista "O Archivo" construiu a memória histórica de Mato Grosso com a publicação de documentos manuscritos e de trabalhos elaborados por historiadores locais. Assim,

${ }^{16}$ Revista Matto-Grosso. Revista Mensal de Sciencias, Lettras, Artes e Variedades. Cuyabá, ano IV, ago. 1907. n. 8. p. 199. 
sempre buscando um espaço para a publicação de seus artigos, bem como para a divulgação da produção de outros raros e dedicados intelectuais que nessa época despontavam, face às eterna dificuldades sempre encontradas, surgiu a idéia de uma revista. Uma publicação séria que enfeixasse não só artigos acerca da história regional, mas também que ensejasse a divulgação de documentos importantes e interessantes para a preservação da memória social de Cuiabá e de Mato Grosso ${ }^{17}$.

$\mathrm{Na}$ apresentação da revista, Antonio Fernandes Souza já pregava a necessidade da fundação de um Instituto Histórico e Geográfico em Cuiabá, editando uma revista que publicasse "documentos relativos á geographia e história do nosso Estado". Pela revista "O Arquivo" passaram textos de Augusto Leverger, João Baptista Prudencio, Francisco de Paula Castro, Epifanio Candido de Souza Pitanga; transcrição de Cartas Régias e documentos relativos à guerra com o Paraguai e à Rusga ${ }^{18}$. Também apareceram textos de Estevão de Mendonça, mais uma vez com as suas "datas mato-grossenses" e de Antonio Fernandes de Souza. Na edição comemorativa de um ano de existência, esses dois últimos autores afirmaram que

foi um anno de lucta incessante em pról da propaganda das tradições historicas de Matto-Grosso e das suas condições geographicas: e o pouco que já fizemos neste sentido, patentêa a grande necessidade, que ha, de se desenvolver amplamente uma publicação desse genero. (...) Em nossa primeira pagina estampamos o retrato do Coronel Antonio Paes de Barros, como penhor de nossa gratidão pelo muito que tem feito em favor da nossa terra natal, dispensando a sua valiosa protecção a $\mathrm{O}$ Archivo, - receptaculo dos acontecimentos que agitaram a alma matto-grossense desde os seus primeiros passos no convivio das sociedades cultas ${ }^{19}$.

Ainda sobre a revista "O Archivo", chama a atenção a grande influência levergeriana em seus editores, que chegaram a editar em 1905 uma edição especial "commemorativa do 25 anniversario do passamento do inolvidavel Barão de Melgaço". Ainda no ano de 1904, o governo do estado participou com produtos

\footnotetext{
${ }^{17}$ SILVA, Paulo Pitaluga Costa e. Apresentação. In: Revista $O$ Archivo. Coleção Fac-similar completa 1904-1906. Varzea Grande: Fundação Julio Campos, 1993.

${ }^{18}$ Sobre este movimento nativista ver CORRÊA, Valmir Batista. História e violência em Mato Grosso: 1817 - 1840. Campo Grande: EdUFMS, 2000.

${ }^{19}$ O Archivo. Revista destinada á vulgarisação de documentos geographicos e historicos do Estado de Matto-Grosso. Cuyabá, ano II, v. 1, dez. 1905.
} 
regionais da exposição de St. Louis (EUA), chegando a imprimir um catálogo ${ }^{20}$ contendo uma "breve noticia sobre o Estado de Matto-Grosso" e informações detalhadas e preciosas da produção regional.

Em 1905, recuperando uma antiga resolução da Assembléia Legislativa de 1880 que autorizava o governo a publicar os trabalhos do Barão de Leverger, o presidente Totó Paes, numa clara influência de Estevão de Mendonça e de Antonio Fernandes de Souza, nomeou-os para selecionar e publicar os trabalhos levegerianos. Como resultado, saiu publicado através da Casa Avelino de Siqueira o livro "Vias de Communicação". Com isto, Leverger atendia a uma solicitação do presidente da província Herculano Pena que por sua vez atendia ao desejo do Ministro de Agricultura do Império de fornecer "informações pormenorisada a respeito da serventia de sua opulenta rede hydrographica" ${ }^{21}$. No entanto, o projetado segundo volume, "Apontamentos Chronologicos de Mato-Grosso", com a destituição e morte de Totó Paes, não chegou a ser publicado. "Os acontecimentos políticos de 1906, porém, determinaram por parte do novo governo outra corrente de idéas, e nada mais se fez até hoje nesse sentido", afirmou Estevão de Mendonça em $1919^{22}$.

Nesse mesmo ano de 1905, Estevão de Mendonça, como professor do Liceu Cuiabano, apresentou um trabalho de cunho didático intitulado "Quadro Chorographico de Matto-Grosso" para apreciação do Conselho Superior de Instrução Pública do Estado. Legalmente, apenas mediante a apreciação deste Conselho é que a obra poderia ser utilizada no próprio Liceu Cuiabano. O parecer aprovado pelo Conselho, no entanto, foi mais além do pretendido pelo autor, sugerindo a sua utilização nas escolas públicas do Estado. Segundo o parecer,

além do merito que revela pela correcção e elegancia de sua forma, vem preencher uma das mais palpitantes necessidades do ensino público primario, fornecendo á mocidade os conhecimentos necessarios da Historia e Geographia do Estado, disciplinas estas que fazem parte das que constituem o programma de

${ }^{20}$ Catalogo dos Artigos enviados pelo Estado de Matto-Grosso para a Exposição de S. Luiz (E. U. da America do Norte). Cuyaba: Off. Pina F, 1904. 84 p. Também apareceu nesse ano um curioso material de divulgação sobre as potencialidades do Estado: BRAZIL. Brief Notice on the State Of Matto-Grosso (Official Publication). Rio de Janeiro: Leuzinger, 1904. 40 p.

${ }^{21}$ TAUNAY, Visconde. Augusto... Op. cit. p. 107.

${ }^{22}$ MENDONÇA, Estevão. Datas... Op. cit. $1^{\circ}$ v. p. 254. 
estudos tanto nas escolas elementares como nas complementares; é de parecer que a mesma obra seja não só considerada de reconhecida utilidade, na forma do art. 184 do vigente regulamento do Lyceu Cuyabano, como adoptada nas escolas publicas do Estado, tão logo seja impressa e exposta á venda ${ }^{23}$.

O compêndio dividia-se em duas partes, sendo a primeira "Descripção physica de Matto-Grosso", e a segunda, "Descripção politica de Matto-Grosso"; "Cidades e villas do Estado". Nota-se neste trabalho de Estevão de Mendonça a clara influência levergeriana, a começar pelo próprio título. A "Revista Matto-Grosso" assim registrou o lançamento do livro afirmando que "esta utilissima publicação, mormente para os nossos collegios e onde quer que se cultive o estudo physico e politico d'este esperançoso Estado, foi officialmente adoptado nos Lycêos Salesiano "S. Gonçalo" e Cuyabano, ambos equiparados ao Gymnasio Nacional"'24.

Mais tarde, e ainda traumatizado com os sangrentos acontecimentos de $1906^{25}$, Estevão de Mendonça participou de uma curiosa polêmica estimulada pelo jornal "O Pharol" sobre a grafia de Cuiabá, com "i” ou “y”. Nesta polêmica, posteriormente editada em um pequeno folheto, Estevão de Mendonça defendeu o termo Cuiabá apoiando-se em vários autores, inclusive Augusto Leverger. Por sua vez, Alipio Guarim defendeu posição contrária afirmando de maneira provocativa que o " facto de Leverger escrevel-a com i não prevalece, visto não ter sido elle litterato, nem philologo, e sim marinheiro intelligentissimo e astronomo" 26 . A resposta veio em forma de "Carta Aberta", na qual Estevão de Mendonça procurou com novos argumentos defender o uso do termo Cuiabá, ressaltando que "quanto á citação do nome de Leverger, fil-o para estar em bôa companhia; se é verdade, com v. affirma, que elle não era litterato, nem philologo, é certo que a sua pujante cultura

\footnotetext{
${ }^{23}$ MENDONÇA, Estevão de. Quadro Chorographico de Matto-Grosso. Cuiabá: Esc. Prof. Salesianas, 1906. p. VII.

${ }^{24}$ Revista Matto-Grosso. Cuyabá, anno III, n. 2, fev. 1906. p. 44.

25 "Os acontecimentos politicos que se desdobraram nesta capital em meiado de 1906 ainda estão vivos á minha memoria. Decorridos dous annos, sinto perfeitamente o esfuziar dos tiroteios fraticidas, o trôar dos canhões e a gritaria atordoante dos grupos que se debatiam por entre o casario da cidade transformado em trincheira". In: MENDONÇA, Estevão de. Uma caturrice. Cuiabá: Esc. Prof. Salesianas, 1908. p. V.
}

${ }^{26}$ Idem, ibidem, p. XII (transcrito de "O Pharol”, de 8.12.1906). 
o induzia necessariamente a conhecer se Cuiabá devia-se escrever com i ou com y, e uma vez que divergio da graphia usada no seu tempo, é por que a considerava errada" 27 . Em "Resposta á Carta Aberta", Alipio Guarim usou novos argumentos para defender o termo Cuyaba, encerrando-a mais uma vez com uma provocação referente à Augusto Leverger: "É fácil explicar o motivo porque o amigo declara em alto e bom som que "a unica fonte segura em cousas que se prendam á historia do Estado, continua a ser o vasto trabalho deixado pelo Barão de Melgaço", e também que

o sr. Ramiz Galvão é o maior conhecedor no Brazil da lingua Portugueza. Pondo de parte sua modestia e desculpando-me da franqueza, direi que o amigo está fanatisado pelos Srs. Barão de Melgaço e Ramiz Galvão, e sendo assim, estou certo, será baldado qualquer contestação, porque ninguem o poderá convencer do contrario. É uma mania como outra qualquer ${ }^{28}$.

Parece que a polêmica continuou no jornal, apesar de não ter sido incluída no folheto. Bem mais tarde, o encerramento da questão veio através de uma nova "Carta Aberta" onde Estevão de Mendonça afirmava a utilização do termo Cuiabá em correspondência oficial, nas leis provinciais e na correspondência particular onde "os exemplos são infinitos: citarei em dez minutos cem casos pelo menos, começando por apontar o nome daquelle inolvidavel servidor da minha terra que se chamou Augusto Leverger - Barão de Melgaço - por quem estou fanatisado" 29 .

Ainda sob o fervor dos acontecimentos políticos, em comemoração à chegada em Cuiabá do novo presidente do estado, coronel Generoso Ponce, seus correligionários publicaram uma "Polyanthéa". Entre os colaboradores estavam alguns que participaram posteriormente da fundação do Instituto Histórico de Mato Grosso, como os desembargadores Joaquim Pereira Mendes, Antonio Fernandes Trigo de Loureiro e Firmo Rodrigues ${ }^{30}$. No ano seguinte, em comemoração do centenário da Abertura dos Portos, o governo federal promoveu uma

${ }^{27}$ Idem, ibidem, p. XIX/XX (transcrito de "O Pharol”, de 15.12.1906).

${ }^{28}$ Idem, Ibidem, p. XXXVIII (transcrito de "O Pharol”, de 9.02.1907).

${ }^{29}$ Idem, ibidem, p. LVII (24.11.1907).

${ }^{30}$ Polyanthéa ao excellentissimo coronel Generoso Paes Leme de Souza Ponce, digno presidente eleito do Estado no dia de sua chegada á esta capital. Homenagem do corpo de redação d'A Colligação. Cuyabá, 23 de julho de 1907. In: PONCE F, Generoso. Op. cit., p.475-480. 
grande Exposição Nacional expondo em pavilhões produtos oriundos dos seus diversos estados. Mato Grosso, além de participar com uma delegação ${ }^{31}$ da qual fazia parte o jovem Virgilio Corrêa Filho, também publicou um "Catálogo"32 dos seus produtos expostos. A exemplo do Catálogo de 1904, este também continha uma "Breve noticia sobre o Estado de Matto-Grosso" e informações sobre os produtos e a economia da região.

No entanto, até esse momento e mesmo com toda essa efervescência cultural, Cuiabá não contava com uma biblioteca pública. Esta instituição cultural foi criada somente em 1912, no governo de Joaquim Augusto da Costa Marques contrariando uma prática usual, com a nomeação para seu organizador de Estevão de Mendonça, que não era um de seus correligionários políticos. "Fruto de azedume partidário, no caso operou-se uma inversão das normas conhecidas; enquanto o jornal da oposição se manifestava com simpatia sôbre o evento, uma ala de correligionarios do govêrno francamente hostilizava a solução daquele problema educacional de vulto", afirmou Estevão de Mendonça ${ }^{33}$, que se exonerou do cargo após a inauguração da biblioteca.

Outro acontecimento relevante ocorrido no governo Costa Marques foi a edição do "Album Graphico do Estado de Matto-Grosso". Fruto de um empreendimento comercial com ostensivo apoio do governo estadual, o "Album Graphico", que demandou dois anos de trabalho e pesquisa, foi editado em Hamburgo em 1914 e contou com a colaboração entre outras pessoas, do próprio presidente Costa Marques, de Estevão de Mendonça e de Carl Lindman. Foi sem dúvida a mais fantástica aventura editorial ocorrida no estado pelas informações contidas e pela esmerada produção gráfica. Segundo seus editores, no prefácio,

com este livro presumimos apresentar o Matto-Grosso moderno aos que, dentro e fôra do Brasil, não o conhecem e desejam conhecel-o. Fizemos por tanto,

\footnotetext{
${ }^{31}$ Sobre a participação de Mato Grosso na Exposição Nacional de 1908, ver PONCE F, Generoso. Op. cit., p. 504/5 e CORRÊA F, Virgílio et alii. Recordações inéditas de Virgílio Correa Filho em seu centenario. Rio de Janeiro, 1987. p. 47/8.

32 EXPOSIÇÃO NACIONAL 1908. Catalogo dos Productos enviados pelo Estado de Matto-Grosso. Na administração do Exmo. Sr. Cel. Generoso P. L. de Souza Ponce. Cuyabá: Avelino de Siqueira, 1908. $144 \mathrm{p}$.
}

${ }^{33}$ MENDONÇA, Estevão. E foi..., op. cit., p. 153. 
este "album" com a intenção e com o desejo de que elle contribuirá para a evolução da vida econômica do Estado, servindo de guia segura de informações geraes para todos quanto tenham por Matto-Grosso algum interesse ${ }^{34}$.

Aconteceu, porém, que o resultado final do "Album Graphico" criou, pelo seu tamanho e peso, sérias dificuldades à sua distribuição. O presidente do estado, Caetano Manoel de Faria e Albuquerque em mensagem à Assembléia Legislativa em 1916, assim relatava o problema:

Está no vosso conhecimento que o governo do Estado adquiriu, por oitenta contos de réis, dous mil exemplares desta publicação, que não é portatil, nem de facil manuseio, como sóe acontecer com as verdadeiras obras de divulgação e propaganda, taes como se escrevem, fundamentalmente inspiradas na preoccupação da lei edonistica do util, isto é, de se obter o maximo proveito com o minimo dispendio, ollimando fazer conhecidas do mundo capitalista, dos chamados investors, as possibilidades economicas que possam attrahir capitaes e braços para as terras que se quer fazer conhecidas, como se pratica em S. Paulo, Minas, Rio Grande do Sul e Estado do Rio.

São verdadeiros guias, succintos e breves, que se lêem mesmo em viagem.

O album de que se trata é de difficil e despendiosa remessa, pelo seu peso, que é de 3.500 grammas, o qual eleva a sua franquia postal a sete mil réis, não acceitando-o o correio pelas suas dimensões, que excedem às regulamentares. Desses dois mil exemplares sobram ainda na Capital Federal creca (sic) de mil, cuja armazenagem o Estado está pagando à casa Sampaio Avelino \& Comp. Desta arte, a sua distribuição gratuita vae-se tornando sobremodo onerosa. Custando ao Estado quarenta mil réis cada volume, a sua remessa o encarece da franquia postal, de que se não sabe quem responde pela sua conveniente: bem póde haver quem o procure para logo o vender por infimo preço.

Encorporado ao patrimonio do Estado, não me animei a autorizar a sua venda, que aliás se me afigura acertada, para que o salvemos das traças; para vêr se, de um tão grande e crescente dispendio, ainda se pòde restituir ao Thesouro uma pequena parcela que $\operatorname{seja}^{35}$.

O governo Caetano Albuquerque envolveu-se em grave crise política, chegando a confrontar-se com a Assembléia Legislativa, o que provocou no estado

\footnotetext{
${ }^{34}$ AYALA, S. Cardoso, SIMON, Feliciano. Album Graphico do Estado de Matto-Grosso (EEUU do Brazil). Corumba/Hamburgo, jan. 1914. 433 p. Annuncios LXIX p.

${ }^{35}$ Mensagem dirigida pelo Exmo. Snr. General Dr. Caetano Manoel de Faria e Albuquerque Presidente do Estado de Matto-Grosso á Assembléa Legislativa ao installar-se a 2a. sessão ordinaria da 10a. legislatura, em 15 de maio de 1916. Cuyabá: Typ. Official, 1916. p.12/3.
} 
uma dualidade político-administrativa. Esta crise com repercussões nacionais levou o presidente da república Wenceslau Braz a decretar em 1917 uma intervenção federal no Mato Grosso. A conciliação ocorreu através de um acordo entre os líderes do Partido Conservador e do Partido Republicano Mato-grossense, assinado no Rio de Janeiro, apoiando uma chapa única ao governo do estado, tendo como presidente D. Francisco de Aquino Corrêa. Governando acima das paixões partidárias e dono de uma sólida formação cultural, D. Aquino caracterizou o seu governo como um período de ressurgimento das manifestações intelectuais, no dizer de Estevão de Mendonça, coincidindo com as comemorações do bicentenário do povoamento de Mato Grosso (ou da fundação de Cuiabá), da fundação do Instituto Histórico de Mato Grosso (01.01.1919) e da fundação do Centro Mato-Grossense de Letras (07.09.1921), depois Academia Mato-grossense de Letras.

Segundo Eurico de Góes, delegado geral da Comissão Organizadora do Dicionário Histórico, Geográfico, Etnografico e Biografico Brasileiro e sócio efetivo do Instituto Histórico e Geográfico Brasileiro, que presidiu a sessão de fundação do Instituto Histórico de Mato Grosso,

ao chegar a Cuiabá, encontrou a idéa da formacão de um Instituto Historico Matto-Grossense, idéa que havia já sido motivo de reuniões diversas de muitos membros da commissão do bi-centenario, os quaes chegaram mesmo a eleger uma directoria provisoria do Instituto em embryão assim como uma commissão incumbida da elaboração dos seus estatutos ${ }^{36}$.

Meses depois, em 8 de abril, com o início das festividades comemorativas do Bicentenário da Colonização de Mato Grosso ocorreu a instalação solene do Instituto Histórico de Mato Grosso e a distribuição do primeiro número de sua revista (ainda no ano de 1919, foi editado o seu segundo número).

O lançamento da Revista do Instituto Histórico de Mato Grosso no ato de sua instalação representou de início a própria consolidação da instituição e também um novo espaço para a reprodução de documentos históricos e para os trabalhos dos historiadores mato-grossenses. Neste primeiro número, que continha a ata de fundação e os estatutos da nova instituição, o presidente do estado, D. Aquino, assinava a apresentação da revista salientando a necessidade de um ór-

\footnotetext{
${ }^{36}$ Ata da fundação do Instituto Histórico de Mato Grosso. In: CORRÊA, D. Francisco de Aquino. Mensagem dirigida á Assembléa Legislativa do Estado ao installar-se a 2a. sessão ordinaria da 11a. legislatura em 7 de setembro de 1919. Cuiabá: Typ. Official, 1919. p. 55/6.
} 
gão que divulgasse a geografia, a história, a etnografia e a arqueologia da região como uma forma de preservação da memória mato-grossense. Ainda do mesmo autor, foi publicado um artigo sobre a colonização de Mato Grosso com o título "Bicentenario de Cuiabá" e poemas sob o título "Terra Natal"37. Continha ainda a transcrições dos trabalhos "Cronicas do Cuiabá" de Joaquim da Costa Siqueira e "Roteiro de Navegação do Rio Paraguai, desde a foz do Rio Sepotuba até a do São Lourenço" de Augusto Leverger. Constavam ainda neste número as primeiras "Notas á Margem" de Virgilio Corrêa Filho ${ }^{38}$ e "Limites de Matto- Grosso com Goyaz" de Filogonio de Paula Corrêa ${ }^{39}$.

Nota-se que além dos inúmeros trabalhos publicados em 1919 a propósito do bicentenário, a questão de limites também provocou uma conflitante situação nos interesses de Mato Grosso, motivando alguns trabalhos sobre o assunto. Este polêmico assunto foi despertado pelo Sexto Congresso Brasileiro de Geografia que tratava

de resolver amigavelmente no referido Congresso, as pendencias de limites ainda existentes entre varios Estados, afim que, ao alvorecer do primeiro centenario da Independencia Nacional, possa a Carta Geral do Brazil apparecer extreme de quaesquer duvidosas linhas de fronteira, está claro que Matto-Grosso, a quem o vizinho Estado de Goiaz persiste em contestar direito ás extensas terras que occupa entre o rio das Mortes e o Pardo, Matto-Grosso, repito, mui particular e vivamente se interessa pelas discussões do mesmo Congresso ${ }^{40}$.

Assim, além do trabalho de Filogonio de Paula Corrêa, a defesa dos interesses de Mato Grosso apareceu uma vez mais no segundo número da Revista

\footnotetext{
${ }^{37}$ Mais tarde D. Aquino publicou em livro "Terra Natal”, edição do centenario, 1922. 2a. ed. "correcta e accrescida de prefacio e 28 producções”. $145 \mathrm{p}$.

${ }^{38}$ Virgilio Corrêa Filho publicou "Notas á Margem" em forma de livro pela secção de obras d'O Estado de S. Paulo, em 1924. 186 p.

${ }^{39}$ Este trabalho foi também publicado separadamente in: CORRÊA, Filogonio de Paula. Limites de Matto-Grosso com Goyaz. Cuiabá: Imp. Official, 1919. Segundo Edvaldo de Assis, "Baseando-se na obra do General Fleming R. de Melo Rego "Limites interestaduais" e em relatorios e mensagens de presidentes da Provincia de Mato Grosso, o autor retoma a questão de limites entre os dois Estados". In: ASSIS, E. Índice Analitico da Revista do Instituto Histórico de Mato Grosso. Cuiabá: Imp. Universitária/UFMT, 1992. p. 23.
}

${ }^{40}$ CORRÊA, D. Francisco de Aquino. A fronteira Matto-Grosso -- Goiaz. Officio dirigido ao Senador Antonio F. Azeredo, Presidente da Delegação Mattogrossense ao Sexto Congresso de Geographia em Bello Horizonte. Cuiabá: Typ. Official, 1919. p. 1. 
do Instituto Histórico de Mato Grosso, sob o título "A fronteira Matto-Grosso Goiaz" um estudo de D. Aquino, depois transformado em livro ${ }^{41}$.

O ex-presidente do estado, Antonio Corrêa da Costa, participou dos festejos do bicentenário com o trabalho "Os predecessores dos Pires de Campos e Anhanguéras", defendendo uma tese curiosa de que "uma fatalidade desviou o curso da história" e bloqueou o expansionismo espanhol em direção ao vasto e rico território mato-grossense, permitindo a sua conquista pelos bandeirantes paulistas. O livro relatava as expedições de Aleixo Garcia, Ayolas, Cabeça de Vaca, Irala e Nuflo Chaves. O assassinato deste último, para o autor, interrompeu a aventura espanhola, pois "certo teria elle descoberto as minas de ouro de Cuyaba e a nova dessa descoberta determinaria o exodo dos hespanhoes de Assumpção e Santa Cruz para Matto-Grosso"42.

Porém, a edição que marcou o ano de 1919 foi "Datas Mato-grossenses" de Estevão de Mendonça, com prefácio de D. Aquino Corrêa. Representava o amadurecimento e a firmeza desse historiador levergeriano com a compreensão de que a "história não é mais a narrativa nua dos acontecimentos de uma nação ou época. É encadeamento lógico e racional dos fatos, registrando como um sismógrafo as pulsações mais obscuras do viver coletivo" ${ }^{43}$. Obra maior do historiador, "Datas Mato-grossenses", nascida timidamente nas páginas da "Revista Matto-Grosso" e de "O Archivo", significou também o resultado de décadas de pesquisas e de coleta de material histórico. Foi, enfim, um garimpeiro com sensibilidade para colher e valorizar informações, fatos e documentos. Segundo D. Aquino,

\footnotetext{
${ }^{41}$ Idem, ibidem. 14 p. e documentos LXXVI p. A Delegação de Mato Grosso representada por Antonio Francisco de Azeredo, Candido M. da S. Rondon e João Barbosa de Faria também publicou um trabalho sobre o mesmo assunto. In: CONFERÊNCIA DE LIMITES INTERESTADOAES (6 Congresso Brazileiro de Geographia). Limites entre os estados de Matto Grosso e Goyaz. Memoria apresentada aos Srs. Delegados do Estado de Goyaz pela Delegação do Estado de Matto Grosso. Rio de Janeiro: Aurora, 1919. 82 p.

${ }^{42}$ COSTA, Antonio Corrêa da. Os predecessores dos Pires de Campos e Anhanguéras. Commemoração do bi-centenario da Fundação da Cidade de Cuyabá. Nictherioy: Esc. Typ. Salesiana, 1918. p. 53. O livro foi lançado somente no ano seguinte. Engenheiro, político e professor de matematica do Liceu Cuiabano, Costa recebeu forte influência de Estevão de Mendonça. In: CORRÊA F, Virgilio. Estevão de Mendonça. Rio de Janeiro, Revista do Instituto Histórico e Geografico Brasileiro. v. 205, out./dez. 1940. p. 395/6.
}

${ }^{43}$ MENDONÇA, Estevão de. E foi..., op. cit., p. 114. 
Aproveitando a magnifica opportunidade do Bicentenario, o Governo do Estado contractou com o Advogado Estevam de Mendonça, a impressão de dois mil exemplares de seu interessante livro histórico intitulado "Datas Mattogrossenses", que enfeixa, em clara synthese, as principaes ephemerides dos nossos dois seculos de vida historica.

Esta obra que se compõe de dois volumes em oitavo, de quasi quatrocentas paginas cada um, ja se acha nitidamente impresso, merecendo lisonjeiras apreciações no meio intellectual em que foi, desde logo, conhecida ${ }^{44}$.

Bem mais tarde, em 1939, Estevão de Mendonça registrava que "As "Datas" tiveram o amparo forte de duas mãos amigas - uma, de D. Aquino Corrêa, proporcionando a publicação do livro; outra, pondo ao meu alcance uma fonte preciosa de pesquisa. O nome virá um dia, se atualizada a obra"45.

Já o parceiro intelectual de Estevão de Mendonça desde o tempo da revista "O Archivo", Antonio Fernandes de Souza, apresentou o trabalho "A Invasão Paraguaya em Matto-Grosso". Foram também incluídos no mesmo livro os estudos "O bi-centenario da fundação de Cuyaba, 1719 - 1919" e "Resenha Histórica - Personagens e Cidades, Villas, Povoações, Rios e Notas Diversas". Segundo o pensamento do autor, "Lutar para ampliar os nossos conhecimentos relativos á nossa patria, divulgando-a atravez dos fatos gloriosos e das licções dos nossos antepassados, da sua historia, emfim, e do estudo do aspecto physico, do solo e sub-solo do seu immenso territorio, que constitue a nossa maior riqueza, é, sem dúvida, um dever de todos os mato-grossenses" ${ }^{46}$.

Também a igreja cuiabana teve participação efetiva nas comemorações do bicentenário, não somente pela ação decisiva do presidente do estado, D. Francisco de Aquino Corrêa, como também com algumas publicações. Muito interessante foi um álbum ilustrado de responsabilidade da Curia Metropolitana de Cuiabá, chamado "A Santa Sé e o Estado de Matto Grosso"47, que serviu para registrar a presença em Cuiabá nos festejos do bicentenário de D. Angelo Jacyntho

\footnotetext{
${ }^{44}$ CORRÊA, D. Francisco de Aquino. Mensagem..., op. cit. p. 54/5.

${ }^{45}$ MENDONÇA, Estevão de. E foi..., op.cit. p. 142. Ver também nota 10.

${ }^{46}$ SOUZA, Antonio Fernandes. A Invasão Paraguaya em Matto-Grosso. Edição commemorativa ao bi-centenario da fundação da cidade de Cuyaba. Cuiabá: J. Pereira Leite, 1919. Prefacio.

${ }^{47}$ A Santa Sé e o Estado de Matto Grosso no bicentenario da fundação de Cuiabá. MDCCXIX MCMXIX. $37 \mathrm{p}$.
} 
Scapardini, Nuncio Apostólico no Brasil. Neste álbum foram publicados documentos relativos ao evento, fotos das autoridades eclesiásticas, civis e militares e uma correspondência com o Vaticano contendo um título honorífico concedido à D. Aquino Corrêa e agradecimentos do Papa pelo recebimento de uma medalha de ouro e da secretaria de estado do Vaticano, também pelo recebimento de uma medalha de prata, ambas comemorativas do bicentenario de Cuiabá.

O bicentenário de Cuiabá também coincidiu com 25 anos da presença dos salesianos em Mato Grosso, o que ensejou a publicação do trabalho "Cinco lustros da Missão Salesiana em Matto-Grosso". Segundo José de Mesquita, “quiz a benemerita Missão Salesiana de Matto Grosso ligar a essa sympathica festividade a publicação de um trabalho que fosse como que a exposição viva dos seus infatigaveis labôres em pról da Instrucção e do Progresso do Estado"48. Com relação à catequese indígena pela Missão Salesiana saiu publicado o trabalho do Pe. Colbacchini, "A Tribu dos Boróros". Escrito em italiano e traduzido por A. Felicio dos Santos, o livro registrava um conjunto de apontamentos e notas sobre o trabalho dos salesianos com os índios boróros. Colbacchini justificava-se perante D. Aquino afirmando que "Resolvi pois apresental o tal qual, como em humilde homenagem a V. Ex. Rvma. por occasião das bodas de prata (25 annos) da missão salesiana neste Estado, para que seja nossa modesta contribuição, em signal de adhesão á grande festa do bi-Centenario de Matto Grosso"49.

Ainda relativo ao ano de 1919, foram publicados "Ephemerides Meteorologicas da Cidade de Cuyaba", do prof. Sylvio Milanese ${ }^{50}$, "Lendas matogrossenses" de Feliciano Galdino de Barros ${ }^{51}$, "Poesias" de José de Mesquita" ${ }^{52}$, "A

${ }^{48}$ Cinco Lustros da Missão Salesiana em Matto-Grosso (Apreciações e apontamentos chronologicos). Cuyaba: Calháo \& Filho, 1919. p. 17.

${ }^{49}$ COLBACCHINI, Pe. Antonio. A Tribu dos Boróros. Rio de Janeiro: Pap. Americana, 1919. p. 1.

${ }^{50}$ MILANESE, Sylvio. Ephemerides Meteorologicas da Cidade de Cuyaba. Rio de Janeiro: Jornal do Brasil, 1919. 107 p. Segundo Henrique Mourize, no prefácio, "O laborioso Prof. Sylvio Milanesi se deu ao trabalho de colligir as observações meteorologicas colhidas, desde mais de quinze annos, por elle e por outros, em Cuyaba, no Observatorio D. Bosco, annexo ao Lyceu Salesiano"(p. 3/4).

${ }^{51}$ BARRos, Feliciano Galdino. Lendas Matogrossenses. Cuiabá: Calháo \& Filho, 1919. 137 p.

${ }^{52}$ MESQUITA, José de. Poesias. Cuiabá: Pereira Leite, 1919. 
Comissão Rondon nas festas comemorativas do Bicentenario de Cuiabá"53 e "O Municipio de Campo Grande" de Rosario Congro ${ }^{54}$.

Mais tarde, em 14 de janeiro de 1926, um fato novo foi acrescido aos acontecimentos de 1919 na cidade de Cuiabá. Foi a assinatura de um decreto pelo então presidente do estado, Estevão Alves Corrêa, juntamente com Virgilio Corrêa Filho, desapropriando como de utilidade pública a casa onde residiu e faleceu Augusto Leverger. Esta medida do governo tomou como base uma solicitação da comissão de intelectuais cuiabanos organizada para este fim, formada entre outros por D. Aquino Corrêa, Estevão de Mendonça, José de Mesquita, Antonio Fernandes de Souza e Firmo José Rodrigues. Posteriormente, o Decreto $n^{\circ} 1$ de 23 de novembro de 1930, assinado pelo interventor federal no estado, Antonino Mena Gonçalves e por Virgilio Corrêa Filho, definia: a "Casa Barão de Melgaço, sita à rua do mesmo nome e de propriedade do Estado, fica destinada, a partir desta data, a ser a sede efetiva do Instituto Histórico de Mato Grosso e do Centro Matogrossense de Letras".

${ }^{53}$ A Comissão Rondon nas festas comemorativas do Bicentenario de Cuiabá. Cuiabá: Imp. Official, 1919. $8 \mathrm{p}$.

${ }^{54}$ CONGRO, Rosario. O Municipio de Campo Grande. Estado de Matto-Grosso. Cuiabá: Pub. Official, 1919. 104 p. Escrito pelo intendente municipal, o trabalho enfocava a história e as atividades econômicas do município. 